\title{
Produção do Superprecoce a Partir de Bezerros Desmamados aos 72 ou 210 Dias de Idade
}

\author{
João Restle ${ }^{1}$, Mikael Neumann², Ivan Luiz Brondani ${ }^{3}$, Dari Celestino Alves Filho ${ }^{4}$, \\ José Henrique Souza da Silva ${ }^{5}$, Jorge Machado Gonçalves ${ }^{6}$, Fernando Kuss ${ }^{7}$
}

\begin{abstract}
RESUMO - O experimento foi conduzido com o objetivo de avaliar o desempenho em confinamento, dos 210 aos 408 dias de idade, de bezerros previamente desmamados aos $72\left(\mathrm{~T}_{72}\right)$ ou $210\left(\mathrm{~T}_{210}\right)$ dias. Foram utilizados 36 machos não castrados da raça Braford $(5 / 8$ Hereford 3/8 Nelore). O peso médio no início do experimento foi de $209 \mathrm{~kg}\left(\mathrm{~T}_{72}\right)$ e $192 \mathrm{~kg}\left(\mathrm{~T}_{210}\right)$. O confinamento compreendeu 30 dias de adaptação dos animais e 168 dias de avaliação, sendo dividido em quatro períodos de 42 dias. A relação volumoso:concentrado foi de 60:40 para o $1^{\circ}$ e $2^{\circ}$ períodos, 50:50 para o $3^{\circ}$ período e 45:55 para o $4^{\circ}$ período. Não houve interação entre idade de desmame e período de avaliação em confinamento para os parâmetros relativos aos consumos médios por animal de matéria seca (CMS) e de energia digestível (CED), expressos em kg/dia e Mcal/dia (CMSD e CEDD), por $100 \mathrm{~kg}$ de peso vivo (CMSP e CEDP) e por unidade de tamanho metabólico (CMSM e CEDM), ao ganho de peso médio diário (GMD), à conversão alimentar (CA) e eficiência energética (EE). Animais desmamados aos 210 dias apresentaram maiores CMSP (2,25 contra 2,07\% PV) e CEDP ( 7,05 contra 6,48\% PV) em relação aos animais desmamados ao 72 dias de idade. Não houve diferença no CMSD (6,75 contra 6,98 kg/dia), no GMD (1,066 contra $1,074 \mathrm{~kg} / \mathrm{dia}), \mathrm{na}$ eficiência de conversão da matéria seca (6,42 contra $6,72 \mathrm{~kg}$ de MS $/ \mathrm{kg}$ ganho de PV) e da energia digestível consumida (20,18 contra 21,13 $\mathrm{Mcal} / \mathrm{kg}$ ganho de PV) em ganho de peso vivo para os animais desmamados aos 72 ou 210 dias de idade, respectivamente. Os pesos de abate e de carcaça quente foram similares entre as duas idades, sendo, respectivamente, de 424 e $232 \mathrm{~kg}$ para os animais do $\mathrm{T}_{72}$ e de 406 e $221 \mathrm{~kg}$ para dos $\mathrm{T}_{210}$. Os resultados mostram que animais desmamados aos 72 dias de idade apresentaram desempenho durante a terminação, pesos de abate e de carcaça similares aos desmamados aos 210 dias.
\end{abstract}

Palavras-chave: Braford, desmame precoce, desmame tradicional, terminação em confinamento

\section{Feedlot Performance of Young Males Weaned at 72 or 210 Days}

ABSTRACT - The experiment was conducted to evaluate the feedlot performance, from 210 to 408 days of age of calves weaned at $72\left(\mathrm{~T}_{72}\right)$ or $210\left(\mathrm{~T}_{210}\right)$ days. Thirty-six non castrated Braford (5/8 Hereford 3/8 Nellore) calves were used. The average weight at the beginning of the experiment was $209\left(\mathrm{~T}_{72}\right)$ and $192 \mathrm{~kg}\left(\mathrm{~T}_{210}\right)$. The whole feedlot period was 168 days, divided in four periods of 42 days. The roughage:concentrate ratio was 60:40 for the first and second periods, 50:50 for the third period and 45:55 for the fourth period. No significant interaction was observed between weaning age and feedlot evaluation period for average daily dry matter intake (DMI) and average daily digestible energy intake (DEI), expressed per animal (DMID and DEID), per $100 \mathrm{~kg}$ of live weight (DMIP and DEIP) and per unit of metabolic weight (DMIM and DEIM), for average daily weight gain (ADG), feed efficiency (FE) and energy efficiency (EE). Animals weaned at 210 days presented higher DMIP (2.25 versus $2.07 \%$ of LW) and DEIP (7.05 versus $6.48 \%$ of LW) than animals weaned at 72 days. No difference was observed for DMID (6.75 versus $6.98 \mathrm{~kg} / \mathrm{day})$, ADG (1.066 versus $1.074 \mathrm{~kg} / \mathrm{day})$, $\mathrm{FE}$ ( 6.42 versus $6.72 \mathrm{~kg}$ of DM/ $\mathrm{kg}$ of LW) and EE (20.18 versus $21.13 \mathrm{Mcal} / \mathrm{kg}$ of LW) for animals weaned at 72 or 210 days. Slaughter and hot carcass weight were similar, being, respectively, 424 and $232 \mathrm{~kg}$ for $\mathrm{T}_{72}, 406$ and $221 \mathrm{~kg}$ for $\mathrm{T}_{210}$ animals. The results showed that animals weaned at 72 days present feedlot performance, slaughter and carcass weight similar to those weaned at 210 days.

Key Words: Braford, early weaning, feedlot performance, normal weaning

\section{Introdução}

A baixa rentabilidade apresentada pela pecuária de corte de ciclo completo atualmente tem forçado o pecuarista a buscar a melhoria dos índices reprodutivos do rebanho. Aumentar a taxa de repro- dução do rebanho é de fundamental importância para incrementar a taxa de desfrute. Sabe-se que a reprodução é uma característica de herdabilidade baixa, altamente influenciada pelos fatores ambientais, entre os quais se destaca a alimentação. Costa et al. (1981) mostraram que a taxa de reprodução dos

\footnotetext{
${ }^{1}$ Engenheiro-Agrônomo, PhD., Pesquisador do CNPq, Professor Titular do Departamento de Zootecnia da UFSM, CEP: $97105-900$, Santa Maria, RS. E.mail: jorestle@ccr.ufsm.br Autor para correspondência.

2 Engenheiro-Agrônomo, MSc., Departamento de Zootecnia da UFSM. E.mail: mikaelneumann@hotmail.com

${ }^{3}$ Zootecnista, MSc., Professor Assistente do Departamento de Zootecnia da UFSM.

${ }^{4}$ Engenheiro-Agrônomo, MSc., Professor Assistente do Departamento de Zootecnia da UFSM.

5 Engenheiro-Agrônomo, PhD, Professor Adjunto do Departamento de Zootecnia da UFSM.

6 Zootecnista.

${ }^{7}$ Aluno do curso de Zootecnia da UFSM.
} 
rebanhos do sul do país pode ser sensivelmente melhorada com o uso de pastagens cultivadas. No entanto, o custo elevado da implantação e produção das pastagens cultivadas tem limitado o seu uso.

Outra técnica de manejo utilizada para melhorar a taxa de reprodução dos rebanhos é o desmame antecipado dos bezerros, que apresenta um custo baixo frente ao benefício obtido (Restle \& Vaz, 1998). Moojen et al. (1994) destacam que o desmame precoce de bezerros é uma das principais alternativas de manejo de bovinos de corte para potencializar a eficiência reprodutiva da vaca e intensificar o sistema de produção de ciclo completo.

O desmame precoce de bezerros de corte é uma técnica bastante difundida entre os produtores no Estado do Rio Grande do Sul. Entre as vantagens do desmame precoce frente ao desmame convencional realizado aos 7 meses de idade dos animais, destacam-se o incremento nos índices de prenhes (Pascoal \& Vaz, 1997; Restle et al., 2001) e a melhoria do estado corporal para os partos subseqüentes (Makarechian et al., 1988). Trabalhos de pesquisa realizados por Barcellos et al. (1995) e Sá et al. (1997) também demonstraram que o desmame precoce de bezerros condiciona a maior ganho de peso das vacas no pós-desmame, melhorando os índices reprodutivos subseqüentes. Moletta \& Perotto (1997) e Restle et al. (2001) relataram que a resposta do desmame precoce é mais acentuada em vacas jovens que ainda estão em crescimento.

Outro aspecto importante para aumentar a produção de carne é a redução da idade de abate para 12-14 meses. Esta técnica, além de aumentar o giro de capital, modifica o sistema de organização das propriedades, pois, a partir do momento em que esses bezerros deixam de ocupar espaço no campo, beneficia e condiciona a um novo manejo de outras categorias.

Segundo Restle et al. (1999a), bezerros desmamados aos 90 dias e mantidos em condição de pastagem apresentaram desempenho semelhante àqueles que permanecem junto à mãe até os 7 meses de idade, atingindo, respectivamente, pesos de 424 e $425 \mathrm{~kg}$ aos 24 meses de idade. Estes resultados demonstram que o desmame precoce conduzido de maneira correta não prejudica o peso de abate dos animais aos 24 meses. No entanto, existem poucas informações a respeito da produção de animais superprecoces com idade de abate aos 14 meses a partir de bezerros desmamados precocemente. Segundo Restle (1997), o manejo em confinamento permite um grau de acaba- mento dos animais jovens dentro dos limites exigidos pelos frigoríficos, atendendo as legislações de incentivo ao abate de animais jovens (Rio Grande do Sul, 1995). Outro aspecto a considerar na produção do superprecoce relaciona-se ao uso de animais inteiros, que possuem melhor eficiência biológica em relação aos animais castrados (Restle et al., 2000), refletindo-se em maior retorno econômico.

O presente experimento foi conduzido com o objetivo de avaliar o desempenho em confinamento, dos 210 aos 408 dias de idade, de bezerros desmamados aos 72 ou 210 dias.

\section{Material e Métodos}

O experimento foi conduzido no Setor de Bovinocultura de Corte do Departamento de Zootecnia da Universidade Federal de Santa Maria, localizada fisiograficamente na Depressão Central do Estado do Rio Grande do Sul, a uma altitude de $95 \mathrm{~m}$. Cartograficamente, localiza-se a $29^{\circ} 43^{\prime}$ de latitude

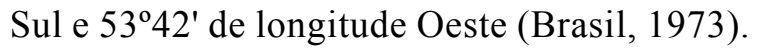

Foi avaliado o desempenho em confinamento de bezerros submetidos a dois tratamentos: desmamados precocemente aos 72 dias de idade $\left(\mathrm{T}_{72}\right)$ ou desmamados aos 210 dias de idade $\left(\mathrm{T}_{210}\right)$, que é o tradicionalmente realizado.

Foram utilizados 36 bezerros Braford ( $5 / 8$ Hereford 3/8 Nelore), não castrados, tomados ao acaso do mesmo rebanho pertencente à fazenda Guatambú de Dom Pedrito (RS). Do nascimento aos 72 dias, os bezerros do $T_{72}$ e $T_{210}$ foram mantidos juntamente nas mesmas condições em campo nativo melhorado. Dos 72 aos 210 dias, os bezerros do $\mathrm{T}_{72}$ foram mantidos em confinamento, recebendo uma dieta contendo, na matéria seca, $50 \%$ de silagem pré-seca de aveia preta (Avena strigosa) e 50\% de concentrado, ao passo que os bezerros do $\mathrm{T}_{210}$ permaneceram ao pé da vaca, no mesmo campo nativo melhorado.

Por ocasião do desmame, os bezerros do $\mathrm{T}_{210}$ pesaram $192 \mathrm{~kg}$, enquanto os do $\mathrm{T}_{72}$, na mesma data, pesaram $209 \mathrm{~kg}$. Imediatamente após o desmame, os bezerros do $\mathrm{T}_{210}$ foram conduzidos para $\mathrm{o}$ confinamento, onde se encontravam os bezerros do $\mathrm{T}_{72}$. Os animais ficaram alojados em oito boxes, quatro por tratamento, cada um com quatro ou cinco bezerros, equilibrados por peso e condição corporal.

Os animais do $\mathrm{T}_{210}$ foram inicialmente submetidos a um período de 30 dias de adaptação às instalações, ao manejo e à dieta alimentar. Já os animais do

R. Bras. Zootec., v.31, n.4, p.1803-1813, 2002 
$\mathrm{T}_{72}$ foram adaptados no mesmo período à nova dieta alimentar. Neste período, realizou-se a aplicação de um vermífugo de amplo espectro e a vacinação preventiva contra febre aftosa, carbúnculo e clostridioses.

O período de confinamento foi de 198 dias, compreendendo a adaptação de 30 dias mais quatro períodos de 42 dias. A composição da dieta alimentar é apresentada na Tabela 1. Como volumoso utilizou-se a mistura de silagens de milho e sorgo, na relação 50:50, com teores médios de MS de 26,45 e 28,03\%, respectivamente. A relação volumoso:concentrado da dieta alimentar foi de 60:40 para a adaptação dos animais e para o primeiro e segundo períodos; 50:50 para o terceiro período; e 45:55 para o quarto período.

O sistema de alimentação foi ad libitum, duas vezes ao dia, a primeira às $8 \mathrm{~h}$ e a segunda às $16 \mathrm{~h}$. $\mathrm{O}$ ajuste do fornecimento da quantidade de alimento in natura foi calculado diariamente, considerando uma sobra de $10 \%$ da matéria seca oferecida em relação à consumida, sendo primeiramente distribuído o volumoso no comedouro e sobre o mesmo o concentrado, realizando-se em seguida a mistura. $\mathrm{O}$ consumo voluntário dos alimentos foi registrado dia- riamente através da pesagem da quantidade oferecida e das sobras do dia anterior.

Os teores médios de proteína bruta e energia digestível da dieta alimentar dos animais durante o período experimental foram, respectivamente, de 13,8 $\pm 2,01 \%$ e de $3,147 \pm 0,04 \mathrm{Mcal} / \mathrm{kg}$ de MS. Utilizouse o sistema NRC (1996) para determinação das exigências nutricionais, no intuito de efetuar o cálculo da dieta alimentar dos animais e a taxa de ganho nos diferentes períodos de avaliação do experimento, visando ganho de peso na ordem de 1,200 kg/dia.

As instalações do confinamento foram do tipo semi-coberto, equipados com bebedouro com bóia automática e comedouros de madeira. No início e final do período de adaptação, bem como no final do período experimental, os animais foram pesados, sempre pela parte da manhã e após um jejum de sólidos de 14 horas, com pesagens intermediárias correspondentes a cada período de avaliação.

Foram coletadas amostras representativas dos componentes da dieta alimentar no início da adaptação e a cada período de avaliação do experimento. Estas amostras foram pré-secas em estufa de ar

Tabela 1 - Composição percentual da dieta alimentar, base na matéria seca, nos diferentes períodos de avaliação do confinamento

Table 1 - Composition (\%) of the experimental diets, dry matter basis, according to the feedlot evaluation periods

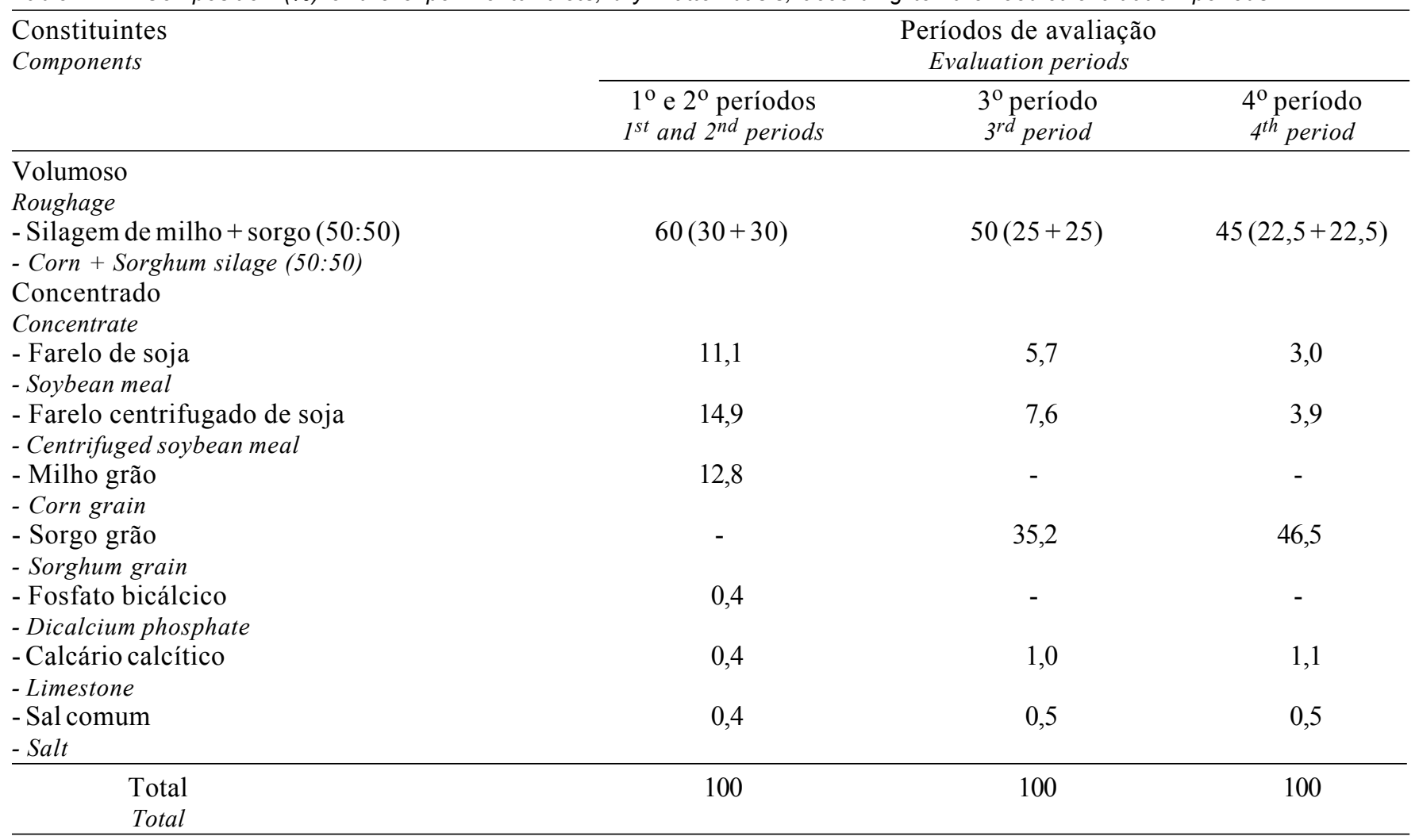

R. Bras. Zootec., v.31, n.4, p.1803-1813, 2002 
forçado a $55^{\circ} \mathrm{C}$, por 72 horas, para determinação do teor de matéria seca, sendo seqüencialmente processadas em moinho tipo Willey com peneira de malha de um milímetro. Posteriormente, nas amostras de cada alimento foram determinados os teores de matéria seca total (MS) e de matéria mineral (MM) por incineração a $550^{\circ} \mathrm{C}$, obtendo-se por diferença o teor de matéria orgânica $(\mathrm{MO}=100-\mathrm{MM})$, nitrogênio total pelo método micro kjeldahl, o qual foi multiplicado pelo fator 6,25 para obtenção do teor de proteína bruta (PB), o teor de extrato etéreo (EE), conforme AOAC (1984); e a digestibilidade in vitro da matéria orgânica (DIVMO) (Tilley \& Terry, 1963). Os teores de fibra em detergente neutro foram determinados pelo método descrito por Van Soest \& Wine (1967). Para o cálculo de energia digestível(ED), utilizaram-se as equações descritas pelo ARC (1980), com base na digestibilidade in vitro da matéria orgânica (DIVMO) e matéria orgânica $(\mathrm{MO})$, em que ED $=($ DIVMO x MO x 19) $\div 4,18$. A partir da ED foi calculada a energia metabolizável (EM), multiplicando-se a ED pelo fator 0,82 .

Os parâmetros estimados foram os consumos médios diários de matéria seca (CMS), expressos em $\mathrm{kg} /$ animal (CMSD), por $100 \mathrm{~kg}$ de peso vivo (CMSP) e por unidade de tamanho metabólico (CMSM), bem como os consumos médios diários de energia digestível (CED), expressos em Mcal/animal (CEDD), por 100 $\mathrm{kg}$ de peso vivo (CEDP) e por unidade tamanho metabólico (CEDM), o ganho de peso médio diário (GMD), a conversão alimentar (CA) e a eficiência energética (EE).

O delineamento experimental foi o inteiramente casualizado, composto por dois tratamentos (duas idades de desmame: 72 e 210 dias), com quatro repetições. Cada unidade experimental foi composta por um lote de quatro ou cinco animais.

Os dados coletados de cada parâmetro foram submetidos à análise de variância, por intermédio do SAS (1993), e as diferenças entre as médias, analisadas pelo teste de F, a 5\% de significância. O modelo estatístico utilizado foi o seguinte: Yijk $=\mathrm{m}+\mathrm{IDi}+$ $\mathrm{Rj}(\mathrm{ID}) \mathrm{i}+\mathrm{Pk}+\left(\mathrm{ID}^{*} \mathrm{P}\right) \mathrm{ik}+$ Eijk em que Yijk = variáveis dependentes; $\mathrm{m}=$ média das observações; IDi = efeito da idade de desmame de ordem " $i$ ", sendo 1 (idade de desmame aos 72 dias) e 2 (idade de desmame aos 210 dias); $\operatorname{Rj}($ ID) $\mathrm{i}=$ efeito aleatório baseado na repetição dentro do tratamento (IDi) (Erro a); $\mathrm{Pk}=$ efeito do período de avaliação de ordem "j", sendo 1 (primeiro período), 2 (segundo período), 3 (terceiro período) e 4 (quarto período); $(\mathrm{ID} * \mathrm{P}) \mathrm{ik}=$ efeito da interação entre o tratamento idade de desmame de ordem "i" e período de avaliação de ordem "k"; e Eijk = erro aleatório residual, assumindo distribuição normal média igual a zero e variância $\sigma^{2}$ (Erro b).

Os dados também foram submetidos à análise de regressão polinomial, considerando a variável período (dias), por meio do procedimento proc reg do programa SAS (1993).

\section{Resultados e Discussão}

Na Tabela 2 constam os resultados da análise bromatológica dos alimentos utilizados na dietas dos animais em confinamento.

Nas Tabelas 3 e 4 são apresentados os resultados médios do CMS e CED, expressos, respectivamente, em kg/animal e Mcal/animal (CMSD e CEDD), por $100 \mathrm{~kg}$ de peso vivo (CMSP e CEDP) e por unidade de peso corporal metabólico (CMSM e CEDM), de acordo com a idade de desmame dos bezerros e com o período de avaliação. Não houve interação $(\mathrm{P}>0,05)$ entre idade de desmame e período de avaliação para CMS e CED, expressos nas diferentes formas.

O CMSD foi similar $(\mathrm{P}>0,05)$ entre os animais do $\mathrm{T}_{72}(6,75 \mathrm{~kg} / \mathrm{dia})$ e $\mathrm{T}_{210}(6,98 \mathrm{~kg} / \mathrm{dia})$, porém, quando expressos em CMSP (2,07 contra 2,25\% PV) e CMSM $\left(87,63\right.$ contra $\left.94,07 \mathrm{~g} / \mathrm{kg}^{0,75}\right)$, os consumos foram superiores $(\mathrm{P}<0,05)$ para os animais desmamados aos 210 dias de idade, apresentando diferença percentual de 8,7 e $7,3 \%$, respectivamente.

Segundo Mertens (1992), o consumo de alimentos é regulado por vários fatores referentes ao animal (peso vivo, nível de produção, estado fisiológico etc), ao alimento (fibra, demanda energética, volume etc) e às condições de alimentação (disponibilidade de alimento, freqüência de alimentação, tempo de acesso ao alimento, entre outros). Além disso, fatores ambientais aos quais o animal está exposto também podem afetar o consumo (NRC, 1996).

No presente experimento, os animais dos dois tratamentos foram submetidos a manejo e dieta diferenciados dos 72 aos 210 dias. Os animais que permaneceram ao pé da vaca tiveram uma dieta mais variada, representada pela queda na produção de leite das vacas com o avanço do período de lactação (Ribeiro et al., 1991) e da qualidade do pasto nativo, que decresce a partir do período de verão (Alves Filho, 1995; Vaz, 1998), apresentando, ao desmame,

R. Bras. Zootec., v.31, n.4, p.1803-1813, 2002 
Tabela 2 - Teores de matéria seca (MS), digestibilidade in vitro da matéria orgânica (DIVMO), matéria orgânica (MO), proteína bruta (PB), extrato etéreo (EE), fibra em detergente neutro (FDN), energia digestível (ED) e energia metabolizável (EM) dos ingredientes das dietas experimentais, com base na matéria seca total

Table 2 - Average percentages of dry matter (DM), in vitro organic matter digestibility (IVOMD), crude protein (CP), organic matter $(O M)$, ether extract (EE), neutral detergent fiber (NDF), digestible energy (DE) and metabolizable energy (ME) of the components of the experimental diets, total dry matter basis

\begin{tabular}{|c|c|c|c|c|c|c|}
\hline $\begin{array}{l}\text { Variável } \\
\text { Variable }\end{array}$ & $\begin{array}{c}\text { Farelo } \\
\text { de soja } \\
\text { Soybean } \\
\text { meal }\end{array}$ & $\begin{array}{l}\text { Farelo de soja } \\
\text { centrifugado } \\
\text { Centrifuged } \\
\text { soybean meal }\end{array}$ & $\begin{array}{l}\text { Grãos de } \\
\text { milho } \\
\text { Corn } \\
\text { grain }\end{array}$ & $\begin{array}{l}\text { Grãos de } \\
\text { sorgo } \\
\text { Sorghum } \\
\text { grain }\end{array}$ & $\begin{array}{c}\text { Silagem de } \\
\text { milho } \\
\text { Corn } \\
\text { silage }\end{array}$ & $\begin{array}{l}\text { Silagem de } \\
\text { sorgo } \\
\text { Sorghum } \\
\text { silage }\end{array}$ \\
\hline & \multicolumn{6}{|c|}{$\%$} \\
\hline $\operatorname{MS}(D M)$ & 88,90 & 90,34 & 88,90 & 89,98 & 26,45 & 28,03 \\
\hline \multirow[t]{2}{*}{ DIVMO (IVOMD) } & 90,59 & 90,21 & 87,20 & 82,26 & 62,03 & 59,25 \\
\hline & \multicolumn{6}{|c|}{$\begin{array}{l}\% \mathrm{MS} \\
\% D M\end{array}$} \\
\hline $\mathrm{MO}(O M)$ & 94,73 & 95,30 & 99,00 & 99,19 & 96,30 & 95,37 \\
\hline $\mathrm{PB}(C P)$ & 48,00 & 32,00 & 8,63 & 9,19 & 7,78 & 6,94 \\
\hline $\mathrm{EE}(E E)$ & 1,82 & 1,67 & 4,08 & 3,00 & 3,87 & 3,21 \\
\hline \multirow[t]{2}{*}{$\mathrm{FDN}(N D F)$} & 16,93 & 35,95 & 13,46 & 16,10 & 56,02 & 57,21 \\
\hline & \multicolumn{6}{|c|}{$\begin{array}{c}\text { Mcal/kg de MS } \\
\text { Mcal/kg of DM }\end{array}$} \\
\hline $\mathrm{ED}(D E)$ & 3,897 & 3,904 & 3,920 & 3,705 & 2,715 & 2,568 \\
\hline $\mathrm{EM}(M E)$ & 3,196 & 3,201 & 3,214 & 3,038 & 2,226 & 2,106 \\
\hline
\end{tabular}

peso de $192 \mathrm{~kg}$. Já os bezerros do $\mathrm{T}_{72}$ foram mantidos no confinamento recebendo uma dieta mais equilibrada e constante, apresentando, aos 210 dias, peso médio de $209 \mathrm{~kg}$.

É possível que os maiores CMSP e CMSM dos animais do $T_{210}$ durante a terminação em confinamento tenham sido, em parte, decorrentes de uma compensação causada pela restrição alimentar qualitativa durante o período de aleitamento. Conforme citado por Preston \& Willis (1982), animais que sofreram previamente restrição alimentar apresentam incremento no consumo de alimentos durante o período em que ocorre o aumento do nível alimentar. Por outro lado, segundo Hogg (1991), a literatura é contraditória em relação ao incremento na quantidade de alimento que os animais consomem após ter ocorrido este período de restrição alimentar. Bail et al. (2000) verificaram durante a terminação em confinamento maior CMSP para os animais que, durante a fase de crescimento, foram mantidos em campo nativo (restrição alimentar qualitativa) em relação aos mantidos em pastagem cultivada $(2,42$ contra $2,17 \%)$.

Os animais do $\mathrm{T}_{210}$ durante o período de aleitamento não tiveram restrição quantitativa de pasto, $\mathrm{e}$ sim qualitativa. A pastagem nativa apresenta elevado teor de FDN e baixa digestibilidade da matéria orgâ- nica, o que força o animal a consumir mais matéria seca para atender as suas exigências, resultando em maior desenvolvimento e capacidade do trato digestivo. Mertens (1994) cita que a capacidade do retículorúmen pode ser alterada, dentro de certos limites, pelo tipo de dieta. Este provável aumento da capacidade digestiva deve ter sido um dos fatores que colaboraram para o maior consumo de matéria seca dos animais do $\mathrm{T}_{210}$ durante a terminação. Myers et al. (1999) concluíram que animais desmamados precocemente (117 dias) e mantidos em pastagem por 82 dias apresentaram maiores peso do retículorúmen e consumo de alimentos durante a fase de terminação em confinamento que animais submetidos a confinamento logo após o desmame.

Verifica-se na Tabela 3 que o CMSP e o CMSM foram superiores $\mathrm{T}_{210}$ tanto no período de adaptação como nos quatro períodos de avaliação, mostrando que esta diferença não foi transitória. Mertens (1992, 1994) relata que são vários os fatores que afetam o consumo alimentar e, segundo Hogg (1991), não existe um mecanismo simples que determina a quantidade de alimento que o animal irá consumir.

De maneira geral, os CMSP e CMSM ocorridos no presente experimento foram inferiores aos obtidos na terminação, a partir dos sete meses de idade, de 
Tabela 3 - Consumo médio diário de matéria seca (CMS) expresso em kg/animal (CMSD), por $100 \mathrm{~kg}$ de peso vivo (CMSP) e por unidade de peso metabólico (CMSM), de bezerros confinados, de acordo com o tratamento e período de avaliação

Table 3 - Means for average daily dry matter intake (DMI) expressed as kg/animal (DMID), per $100 \mathrm{~kg}$ of live weight (DMIP) and per unit of metabolic weight (DMIM), of feedlot calves, according to treatment and evaluation period

Tratamento

Períodos de avaliação

Treatment

Evaluation periods

Média dos períodos

\begin{tabular}{|c|c|c|c|c|c|c|}
\hline \multirow[t]{2}{*}{ Treatment } & \multicolumn{5}{|c|}{ Evaluation periods } & \multirow[t]{2}{*}{ Mean of periods } \\
\hline & $\begin{array}{c}\text { Adaptação } \\
\text { Adaptation }\end{array}$ & $\begin{array}{l}1^{\mathrm{o}} \text { Período } \\
1^{\text {st }} \text { Period }\end{array}$ & $\begin{array}{l}2^{\circ} \text { Período } \\
2^{\text {nd }} \text { Period }\end{array}$ & $\begin{array}{l}3^{\circ} \text { Período } \\
3^{\text {rd }} \text { Period }\end{array}$ & $\begin{array}{l}4^{\circ} \text { Período } \\
4^{\text {th }} \text { Period }\end{array}$ & \\
\hline \multirow{5}{*}{$\begin{array}{l}72 \text { dias } \\
72 \text { days } \\
210 \text { dias } \\
210 \text { days } \\
\text { Média } 1 \\
\text { Mean }\end{array}$} & \multicolumn{6}{|c|}{$\begin{array}{l}\text { CMSD (kg/dia) } \\
D M I D(\mathrm{~kg} / \text { dia })\end{array}$} \\
\hline & 5,19 & 5,76 & 6,15 & 7,09 & 7,99 & $6,75^{\mathrm{A} *}$ \\
\hline & 5,23 & 5,83 & 6,47 & 7,42 & 8,21 & $6,98^{\mathrm{A}}$ \\
\hline & 5,21 & 5,79 & 6,31 & 7,26 & 8,10 & \\
\hline & \multicolumn{6}{|c|}{$\begin{array}{c}\text { CMSP }(\% \mathrm{PV}) \\
D M I P(\% \text { of } L W)\end{array}$} \\
\hline $\begin{array}{l}72 \text { dias } \\
72 \text { days }\end{array}$ & 2,35 & 2,23 & 2,00 & 2,01 & 2,03 & $2,07^{\mathrm{B}}$ \\
\hline $\begin{array}{l}210 \text { dias } \\
210 \text { days }\end{array}$ & 2,58 & 2,40 & 2,20 & 2,20 & 2,17 & $2,25^{\mathrm{A}}$ \\
\hline Média $^{2}$ & 2,46 & 2,32 & 2,10 & 2,11 & 2,10 & \\
\hline Mean & \multicolumn{6}{|c|}{$\begin{array}{c}\text { CMSM }\left(\mathrm{g} / \mathrm{kg}^{0,75}\right) \\
\text { DMIM }\left(\mathrm{g} / \mathrm{kg}^{75}\right)\end{array}$} \\
\hline $\begin{array}{l}72 \text { dias } \\
72 \text { days }\end{array}$ & 90,56 & 89,32 & 83,70 & 87,23 & 90,29 & $87,63^{\mathrm{B}}$ \\
\hline $\begin{array}{l}210 \text { dias } \\
210 \text { days }\end{array}$ & 97,42 & 94,83 & 91,22 & 94,41 & 95,80 & $94,07^{\mathrm{A}}$ \\
\hline $\begin{array}{l}\text { Média }^{3} \\
\text { Mean }\end{array}$ & 93,99 & 92,07 & 87,46 & 90,82 & 93,05 & \\
\hline
\end{tabular}

* Médias seguidas de letras maiúsculas diferentes na coluna, para cada variável, diferem $(P<0,05)$ pelo teste $F$.

$1 Y=4,9028+0,018316 D\left(R^{2}=0,8697 ; C V=5,89 ; P<0,0001\right)$, em que $D=$ dias de confinamento

$2 Y=2,3181-0,001461 D\left(R^{2}=0,2340 ; C V=6,79 ; P<0,0166\right)$.

${ }^{3} Y=101,1723-0,271658 D+0,001311 D^{2}\left(R^{2}=0,1925 ; C V=5,87 ; P<0,1060\right)$.

Means in the column followed by different capital letters, for each variable, are different $(P<.05)$ by $F$ test.

${ }^{1} Y=4.9028+0.018316 D(R$-square $=0.8697 ; C V=5.89 ; P<.0001)$, where $D=$ feedlot days .

$2 Y=2.3181-0.001461 D(R$-square $=0.2340 ; C V=6.79 ; P<.0166)$.

${ }^{3} Y=101.1723-0.271658 D+0.001311 D^{2}(R$-square $=0.1925 ; C V=5.87 ; P<.1060)$.

animais superprecoces e relatados por Flores (1997) $\left(\mathrm{CMSP}=2,25 \% ; \mathrm{CMSM}=94,9 \mathrm{~g} / \mathrm{kg}^{0,75}\right)$, Restle et al. $(1997)\left(\mathrm{CMSP}=2,64 \% ; \mathrm{CMSM}=107,6 \mathrm{~g} / \mathrm{kg}^{0,75}\right)$, Restle et al. (1999b) (CMSP $=2,26 \%$; $\mathrm{CMSM}=$ $\left.124,0 \mathrm{~g} / \mathrm{kg}^{0,75}\right)$ e Pelegrini et al. (2000) $(\mathrm{CMSP}=$ 2,85\%; CMSM = 108,2 $\mathrm{g} / \mathrm{kg}^{0,75}$ ).

Os consumos de matéria seca expressos nas diferentes formas foram afetados $(\mathrm{P}<0,05)$ pelo período de avaliação do confinamento. Verifica-se que o CMSD mostrou comportamento linear, apresentando incremento de $18,32 \mathrm{~g}$ no consumo de alimentos a cada dia (D) de avanço no período dos animais em confinamento. Do início ao final do período de 168 dias de confinamento, o CMSD elevou-se em 39,90\%, que é justificado pelo desenvolvimento corporal dos animais, com conseqüente incremento da capacidade ingestiva diária de MS, e pelo incremento da participação da fração concentrada na dieta alimentar dos animais com o avanço do confinamento. Pascoal et al. (2000) observaram aumento de $63 \%$ no CMSD dos animais em um período de 84 dias de confinamento, utilizando bezerros desmamados aos 66 dias de idade, concluindo que o consumo de MS, nas suas diferentes formas de expressão, aumentou linearmente com o avanço do período do confinamento, demonstrando o aumento da capacidade ingestiva dos bezerros. 
A partir dos dados apresentados na Tabela 3, constata-se que o CMSP mostrou comportamento linear decrescente frente ao período de confinamento, diminuindo do primeiro para o segundo período na ordem de 9,48\%, mantendo-se estável no terceiro e quarto períodos de avaliação subseqüentes. Quando o CMS foi expresso por unidade de tamanho metabólico, observou-se que o consumo de alimentos decresceu do primeiro $\left(92,07 \mathrm{~g} / \mathrm{kg}^{0,75}\right)$ para o segundo $\left(87,46 \mathrm{~g} / \mathrm{kg}^{0,75}\right)$ período na ordem de $5,01 \%$, no entanto aumentou progressivamente no terceiro $(90,82$ $\left.\mathrm{g} / \mathrm{kg}^{0,75}\right)$ e quarto $\left(93,05 \mathrm{~g} / \mathrm{kg}^{0,75}\right)$ períodos subseqüentes, o que determinou uma resposta quadrática frente aos períodos de avaliação, com ponto de mínimo consumo aos 103,6 dias de confinamento.

O menor CMSM observado no segundo período foi decorrente das características da dieta alimentar oferecida aos animais, pois no primeiro e segundo períodos de confinamento a relação volumoso:concentrado utilizada foi de 60:40, alterando-se para 50:50 no terceiro e para 55:45 no quarto período. Esta mudança da relação volumoso:concentrado durante os períodos de confinamento favoreceu o incremento do CMSM, devido ao aumento dos teores de matéria seca e da concentração de energia digestível na dieta alimentar. Ponderações feitas por McDonald et al. (1991) evi-

Tabela 4 - Consumo médio diário de energia digestível (CED), expresso em Mcal/animal (CEDD), por $100 \mathrm{~kg}$ de peso vivo (CEDP) e por unidade de peso metabólico (CEDM), de bezerros confinados, de acordo com o tratamento e período de avaliação

Table 4 - Means for average daily digestible energy intake (DEI) expressed as Mcal/animal (DEID), per $100 \mathrm{~kg}$ of live weight (DEIP) and per unit of metabolic weight (DEIM), of feedlot calves, according to treatment and evaluation period

\begin{tabular}{|c|c|c|c|c|c|c|}
\hline \multirow[t]{2}{*}{$\begin{array}{l}\text { Tratamento } \\
\text { Treatment }\end{array}$} & \multicolumn{5}{|c|}{$\begin{array}{l}\text { Períodos de avaliação } \\
\text { Evaluation periods }\end{array}$} & \multirow{2}{*}{$\begin{array}{l}\text { Média dos períodos } \\
\text { Mean of periods } \\
\text { o }\end{array}$} \\
\hline & $\begin{array}{l}\text { Adaptação } \\
\text { Adaptation }\end{array}$ & $\begin{array}{l}1^{\circ} \text { Período } \\
1^{\text {st }} \text { Period }\end{array}$ & $\begin{array}{l}2^{\circ} \text { Período } \\
2^{\text {nd }} \text { Period }\end{array}$ & $\begin{array}{l}3^{\circ} \text { Período } \\
3^{\text {rd }} \text { Period }\end{array}$ & $\begin{array}{l}4^{\circ} \text { Período } \\
4^{\text {th }} \text { Period }\end{array}$ & \\
\hline & \multicolumn{6}{|c|}{$\begin{array}{c}\operatorname{CEDD}(\mathrm{Mcal} / \mathrm{dia}) \\
D E I D(\text { Mcal/day })\end{array}$} \\
\hline $\begin{array}{l}72 \text { dias } \\
72 \text { davs }\end{array}$ & 16,14 & 17,91 & 19,11 & 22,34 & 25,45 & $21,21^{\mathrm{A} *}$ \\
\hline $\begin{array}{l}210 \text { dias } \\
210 \text { days }\end{array}$ & 16,26 & 18,11 & 20,12 & 23,36 & 26,13 & $21,93^{\mathrm{A}}$ \\
\hline $\begin{array}{l}\text { Média }{ }^{1} \\
\text { Mean }\end{array}$ & 16,20 & \\
\hline & \multicolumn{6}{|c|}{$\begin{array}{l}\text { CEDP }(\% \mathrm{PV}) \\
D E I P(\% \text { of } L W)\end{array}$} \\
\hline $\begin{array}{l}72 \text { dias } \\
72 \text { days }\end{array}$ & 7,32 & 6,92 & 6,21 & 6,34 & 6,45 & $6,48^{\mathrm{B}}$ \\
\hline & 8,01 & 7,47 & 6,85 & 6,94 & 6,92 & $7,05^{\mathrm{A}}$ \\
\hline \multirow{2}{*}{$\begin{array}{l}\text { Média }^{2} \\
\text { Mean }\end{array}$} & 7,66 & 7,20 & 6,53 & 6,64 & 6,69 & \\
\hline & \multicolumn{6}{|c|}{$\begin{array}{c}\operatorname{CEDM}\left(\mathrm{kcal} / \mathrm{kg}^{0,75}\right) \\
\text { DEIM }\left(\text { Kcal } / \mathrm{kg}^{.75}\right)\end{array}$} \\
\hline $\begin{array}{l}72 \text { dias } \\
72 \text { days }\end{array}$ & 282,22 & 277,68 & 260,22 & 274,68 & 287,49 & $275,02^{\mathrm{B}}$ \\
\hline $\begin{array}{l}210 \text { dias } \\
210 \text { days }\end{array}$ & 302,34 & 294,84 & 283,60 & 297,29 & 305,03 & $295,19 \mathrm{~A}$ \\
\hline $\begin{array}{l}\text { Média }{ }^{3} \\
\text { Mean }\end{array}$ & 292,28 & 286,26 & 271,91 & 285,99 & 296,26 & \\
\hline
\end{tabular}

* Médias seguidas de letras maiúsculas diferentes na coluna, para cada variável, diferem $(P<0,05)$ pelo teste $F$.

${ }^{1} Y=14,9422+0,061975 D\left(R^{2}=0,8789 ; C V=6,08 ; P<0,0001\right)$, em que $D=$ dias de confinamento.

${ }^{2} Y=8,2899-0,031404 D+0,000129 D^{2}(R$-square $=0.3428 ; C V=6,19 ; P<0,0122)$.

${ }^{3} Y=316,8978-0,927661 D+0,004719 D^{2}(R$-square $=0.2890 ; C V=5.88 ; P<0,0278)$.

Means in the column followed by different capital letters, for each variable, are different $(P<.05)$ by $F$ test.

${ }^{1} Y=14.9422+0.061975 D(R$-square $=0.8789 ; C . V .=6.08 ; P<.0001)$, where $D=$ feedlot days.

${ }^{2} Y=8.2899-0.031404 D+0.000129 D^{2}\left(R^{2}=0.3428 ; C V=6.19 ; P<0.0122\right)$.

${ }^{3} Y=316.8978-0.927661 D+0.004719 D^{2}\left(R^{2}=0.2890 ; C V=5.88 ; P<0.0278\right)$.

R. Bras. Zootec., v.31, n.4, p.1803-1813, 2002 
denciam que o teor de matéria seca da dieta alimentar atua diretamente como um fator controlador no comportamento de ingestão de alimentos dos ruminantes, visto que a água presente nos alimentos resulta em espaço ocupado no trato gastrointestinal. Eifert et al. (2000), trabalhando com bezerros Braford desmamados aos 88 dias de idade em confinamento, verificaram que a elevação dos níveis de concentrado na dieta proporcionou respostas lineares e positivas no CMSP e CMSM, justificando os resultados, entre outros fatores, pela diminuição do tamanho das partículas e pela maior densidade física da dieta, que permitiu maior taxa de passagem pelo rúmen (Owens \& Goetsch, 1993), e pela redução dos teores de FDN da dieta, a qual tem relação negativa com o CMS em ruminantes (Mertens, 1992; Van Soest, 1994).

Os CED médios (Tabela 4) foram similares ( $\mathrm{P}>0,05)$, quando expressos por animal $(21,21$ contra $21,93 \mathrm{Mcal} / \mathrm{dia})$, para animais com idade de desmame de 72 ou 210 dias. Porém, quando expresso como porcentagem de peso vivo $(6,48$ contra $7,05 \%)$ e por unidade de tamanho metabólico (275,02 contra 295,19 $\mathrm{kcal} / \mathrm{kg}^{0,75}$ ), animais desmamados aos 72 dias apresentaram menores CED $(\mathrm{P}<0,05)$ frente aos desmamados aos 210 dias, mostrando uma diferença percentual de 8,08 e $6,83 \%$, respectivamente, a favor dos animais desmamados aos 210 dias, o que, no entanto, não causou efeito significativo sobre o ganho de peso e a conversão alimentar dos animais (Tabela 5).

Flores (1997), avaliando diferentes grupos genéticos de bovinos de corte, encontrou CEDP com valores variando entre 6,7 e $7,4 \%$. Valores semelhantes ao do presente trabalho de pesquisa, para o CEDM, foram observados por Restle et al. (1997) com consumo médio de $295,2 \mathrm{kcal} / \mathrm{kg}^{0,75}$ para bezerros Hereford desmamados aos 210 dias. Já Restle et al. (1999c) verificaram CEDM superiores ao do presente trabalho, com valores de 299,311 e 298 $\mathrm{kcal} / \mathrm{kg}^{0,75}$, em bezerros Hereford, $1 / 2$ Jersey $1 / 2$ Hereford e 5/8 Hereford 3/8 Nelore desmamados aos 210 dias e confinados logo após durante 193 dias.

Os CED expressos nas diferentes formas foram afetados $(\mathrm{P}<0,05)$ pelo período de avaliação do confinamento. Para o CEDD observou-se comportamento linear crescente frente aos períodos do confinamento, apresentando incremento a cada dia de confinamento no consumo de energia de $61,98 \mathrm{cal}$. No período total do confinamento de 168 dias, o CEDD aumentou em 43,20\%, o que é justificado pelo aumento linear do CMSD (Tabela 3) e pelo incre- mento da participação da fração concentrada na dieta alimentar dos animais com o avanço do confinamento (Tabela 1). Já para o CEDP e CEDM a relação com o período de confinamento foi quadrática. Analisando os dados médios dos períodos do confinamento (Tabela 4), observa-se que o CMSP e CEDM decresceram do primeiro para o segundo período, aumentando no terceiro e quarto períodos de avaliação subseqüentes, determinando, conforme a equação de regressão, os pontos de mínimos consumos, respectivamente, aos 121,7 e 98,3 dias de confinamento.

Não houve interação significativa entre idade de desmame e período de confinamento para as variáveis ganho de peso médio diário (GMD), conversão alimentar (CA) e eficiência energética (EE). Na média, os GMD dos animais foram similares $(\mathrm{P}>0,05)$ para as idades de desmame de 72 (1,066 kg/dia) e 210 dias $(1,074 \mathrm{~kg} / \mathrm{dia})$. Também não se observou diferença significativa na eficiência de transformação da matéria seca consumida em ganho de peso $(6,42$ contra $6,72 \mathrm{~kg}$ de MS/kg de PV), bem como transformação da energia digestível consumida em ganho de peso $(20,18$ contra $21,13 \mathrm{Mcal} / \mathrm{kg}$ de PV), respectivamente, às idades de desmame de 72 e 210 dias.

Resultados semelhantes foram obtidos por Restle et al. (1999c), avaliando o desempenho bezerros de diferentes grupos genéticos desmamados aos 210 dias e confinados por um período de 193 dias, com valores médios de 1,050 kg/dia para o GMD, 6,95 kg de MS/kg de PV para CA e 18,98 Mcal/kg de PV. Já Myers et al. (1999) observaram maior GMD e melhor CA em animais também desmamados precocemente e abatidos com idade similar à do presente experimento, porém com níveis mais altos de concentrado na dieta.

O GMD, a CA e a EE foram afetados $(\mathrm{P}<0,05)$ pelo período de avaliação do confinamento. Verificase que o GMD mostrou comportamento linear decrescente com o avanço do período do confinamento, com redução de $1,96 \mathrm{~g}$ a cada dia de confinamento. Do início ao final do confinamento (168 dias), o ganho de peso decresceu em $21,66 \%$. Verifica-se que o incremento do nível de concentrado do primeiro e segundo períodos $(40 \%)$ para o terceiro $(50 \%)$ e quarto períodos $(55 \%)$ subseqüentes do confinamento não foi suficiente para manter o mesmo ritmo de ganho de peso observado no primeiro período, o que foi justificado pelo baixo CMSP $(2,1 \%)$ observado no segundo, terceiro e quarto períodos de avaliação, fator que limitou o maior CED nas diferentes formas de expressão, as quais se relacionam diretamente com o GMD.

R. Bras. Zootec., v.31, n.4, p.1803-1813, 2002 
Na análise da conversão alimentar e da eficiência energética dos animais frente aos períodos de confinamento, observou-se comportamento linear crescente (Tabela 5). As equações de regressão mostraram que a CA e EE pioraram com o avanço da duração em dias do confinamento dos animais, onde, a cada dia de confinamento, houve aumento de consumo de $28,57 \mathrm{~g}$ de MS e de $61,97 \mathrm{cal}$, para a mesma taxa de ganho de peso. Analisando o período total do confinamento (168 dias), observou-se redução acentuada na eficiência de transformação da matéria seca consumida $(77,26 \%)$ e da energia digestível consumida $(81,39 \%)$ em ganho de peso - resposta obtida pelo decréscimo linear do GMD frente ao avanço dos períodos de confinamento dos animais, visto que o CMSP decresceu somente do primeiro para o segundo período, mantendo-se estável no terceiro e quarto períodos subseqüentes.

Embora o peso inicial dos animais tenha sido numericamente superior para os animais desmamados aos 72 dias $(209 \mathrm{~kg})$ em relação aos que ficaram ao pé da vaca até a idade de 210 dias $(192 \mathrm{~kg})$, o ganho de peso foi similar durante a terminação em confinamento, mantendo-se praticamente a mesma diferença no peso final $(424 \mathrm{e} 406 \mathrm{~kg})$. O peso de carcaça dos animais do $\mathrm{T}_{72}$ foi de $232 \mathrm{~kg}$ com cobertura de gordura de $4,6 \mathrm{~mm}$, estando dentro dos limites mínimos $(230 \mathrm{~kg}$ de peso e gordura de cobertura

Tabela 5 - Ganho de peso médio diário (GMD), conversão alimentar (CA) e eficiência energética (EE), de bezerros confinados, de acordo com o tratamento e período de avaliação

Table 5 - Means for average daily weight gain (ADG), feed efficiency (FE) and energy efficiency (EE), of feedlot calves, according to the treatment and evaluation period

\begin{tabular}{|c|c|c|c|c|c|c|}
\hline \multirow[t]{2}{*}{$\begin{array}{l}\text { Tratamento } \\
\text { Treatment }\end{array}$} & \multicolumn{5}{|c|}{$\begin{array}{l}\text { Períodos de avaliação } \\
\text { Evaluation periods }\end{array}$} & \multirow{2}{*}{$\begin{array}{l}\text { Média dos períodos } \\
\text { Mean of periods }\end{array}$} \\
\hline & $\begin{array}{l}\text { Adaptação } \\
\text { Adaptation }\end{array}$ & $\begin{array}{l}1^{\circ} \text { Período } \\
1^{\text {st }} \text { Period }\end{array}$ & $\begin{array}{l}2^{\circ} \text { Período } \\
2^{\text {nd }} \text { Period }\end{array}$ & $\begin{array}{l}3^{\circ} \text { Período } \\
3^{\text {rd }} \text { Period }\end{array}$ & $\begin{array}{l}4^{\circ} \text { Período } \\
4^{\text {th }} \text { Period }\end{array}$ & \\
\hline & \multicolumn{6}{|c|}{$\begin{array}{l}\mathrm{GMD}(\mathrm{kg} / \mathrm{dia}) \\
A D G(\mathrm{~kg} / \text { day })\end{array}$} \\
\hline 72 dias & 1,128 & 1,165 & 1,084 & 1,045 & 0,965 & $1,066^{\mathrm{A} *}$ \\
\hline & 0,987 & 1,292 & 1,050 & 0,997 & 0,958 & $1,074^{\mathrm{A}}$ \\
\hline \\
\hline & \multicolumn{6}{|c|}{$\begin{array}{l}\mathrm{CA}(\mathrm{CMSD} / \mathrm{GMD}) \\
F E(D M I D / A D G)\end{array}$} \\
\hline $\begin{array}{l}72 \text { dias } \\
72 \text { days }\end{array}$ & 4,63 & 4,95 & 5,68 & 6,78 & 8,28 & $6,42^{\mathrm{A}}$ \\
\hline 210 dias & 5,97 & 4,56 & 6,20 & 7,56 & 8,56 & $6,72^{\mathrm{A}}$ \\
\hline $\begin{array}{l}\text { Médiaia }^{2} \\
\text { Mean }\end{array}$ & 5,30 & 4,75 & 5,94 & 7,17 & 8,42 & \\
\hline & \multicolumn{6}{|c|}{$\begin{array}{l}\mathrm{EE}(\mathrm{CEDD} / \mathrm{GMD}) \\
E E(D E I D / A D G)\end{array}$} \\
\hline $\begin{array}{l}72 \text { dias } \\
72 \text { days }\end{array}$ & 14,31 & 15,38 & 17,65 & 21,34 & 26,36 & $20,18^{\mathrm{A}}$ \\
\hline $\begin{array}{l}\text { Média }^{3} \\
\text { Mean }\end{array}$ & 15,39 & 14,78 & 18,46 & 22,57 & 26,81 & \\
\hline
\end{tabular}

* Médias seguidas de letras maiúsculas iguais na coluna, para cada variável, não diferem $(P<0,05)$ pelo teste $F$.

${ }^{1} \mathrm{Y}=1,2819-0,001962 \mathrm{D}\left(\mathrm{R}^{2}=0,5278 ; \mathrm{CV}=9,54 ; \mathrm{P}<0,0001\right)$, onde $\mathrm{D}=$ dias de confinamento.

$2 Y=3,5137+0,028567 D\left(R^{2}=0,9314 ; C V=6,79 ; P<0,0001\right)$

$3 \mathrm{Y}=14,9423+0,061975 \mathrm{D}\left(\mathrm{R}^{2}=0,8789 ; \mathrm{CV}=6,08 ; \mathrm{P}<0,0001\right)$

Means in the column followed by equal capital letters, for each variable, do not differ $(P<.05)$ by $F$ test.

${ }^{1} Y=1.2819-0.001962 D(R$-square $=0.5278 ; C V=9.54 ; P<.0001)$, where $D=$ feedlot days.

${ }^{2} Y=3.5137+0.028567 D(R$-square $=0.9314 ; C V=6.79 ; P<.001)$

${ }_{3} Y=14.9423+0.061975 D(R$-square $=0.8789 ; C V=6.08 ; P<.0001)$.

R. Bras. Zootec., v.31, n.4, p.1803-1813, 2002 
de $3 \mathrm{~mm}$ ) exigidos pelos frigoríficos brasileiros. Já no $\mathrm{T}_{210}$ o peso de carcaça foi numericamente $(\mathrm{P}>0,05)$ inferior $(214 \mathrm{~kg})$, com gordura de cobertura de 4,2 mm. Embora o peso de carcaça tenha sido inferior aos $230 \mathrm{~kg}$, estas carcaças não seriam penalizadas no preço, já que no sul do país houve uma mudança nos últimos cinco anos por parte dos frigoríficos, que estão aceitando carcaças com peso acima de $180 \mathrm{~kg}$, desde que apresentem o mínimo de $3 \mathrm{~mm}$ de gordura de cobertura. Analisando as características de carcaça de machos castrados abatidos aos 24 meses e previamente desmamados aos 90 ou 210 dias de idade, Restle et al. (1999d) também não verificaram diferenças significativas para peso de abate aos 24 meses e características de carcaça, entre animais castrados desmamados aos 90 ou 210 dias.

\section{Conclusões}

Animais desmamados aos 72 dias apresentaram, durante a fase de terminação em confinamento, ganho de peso, conversão alimentar e eficiência energética similares aos desmamados tradicionalmente aos 210 dias.

A produção do superprecoce a partir de animais desmamados aos 72 dias de idade define características de carcaça similares aos desmamados aos 210 dias, com peso e espessura de gordura de cobertura adequados às exigências para comercialização.

\section{Literatura Citada}

AGRICULTURAL RESEARCH COUNCIL - ARC. The nutrients requirements of ruminants livestock. Technical review by on Agricultural Research Council Working Party, London, 1980. 351p.

ALVES FILHO, D.C. Evolução do peso e desempenho anual de um rebanho de cria constituído por fêmeas de diferentes grupos genéticos. Santa Maria: Universidade Federal de Santa Maria, 1995. 183p. Dissertação (Mestrado em Zootecnia) - Universidade Federal de Santa Maria, 1995.

ASSOCIATION OF OFFICIAL ANALYTICAL CHEMISTS AOAC. Official methods of analysis. 14.ed. Washington, D.C.: 1984. 1141p.

BAIL, C.A.T.; BRONDANI, I.L.; RESTLE, J. Níveis de concentrado na fase de terminação em confinamento para novilhos previamente mantidos em pastagem nativa ou cultivada. Ciência Rural, v.30, n.1, p.151-157, 2000.

BARCELLOS, J.O.J.; LOBATO, J.F.P.; SILVA, M.D. Desempenho ponderal de vacas e terneiros de corte submetidos ao desmame aos 70 ou 120 dias de idade. In: REUNIÃO ANUAL DA SOCIEDADE BRASILEIRA DE ZOOTECNIA, 32. 1995, Brasília. Anais... Brasília: Sociedade Brasileira de Zootecnia, 1995. p.426-427.

R. Bras. Zootec., v.31, n.4, p.1803-1813, 2002
BRASIL. Ministério da Agricultura. Levantamento de reconhecimento dos solos do Estado do Rio Grande do Sul. Recife: Departamento Nacional de Pesquisa AgropecuáriaDivisão de Pesquisas Pedológicas. 1973. 430p. (Boletim Técnico, 30).

COSTA, A.M.; RESTLE, J.; MULLER, L. Influência da pastagem cultivada no desempenho reprodutivo de vacas com cria ao pé. Ciência Rural, v.11, n.4, p.187-200, 1981.

EIFERT, E.C.; RESTLE, J.; PASCOAL, L.L. et al. Desempenho de terneiros de corte desmamados precocemente alimentados com silagem de sorgo associada a diferentes níveis de concentrado. In: REUNIÃ̃O ANUAL DA SOCIEDADE BRASILEIRA DE ZOOTECNIA, 37., 2000, Viçosa. Anais... São Paulo: SBZ/Gmosis, [2000] 17par. CD-ROM. Nutrição de Ruminantes. NUR-140.

FLORES, J.L.C. Desempenho em confinamento de terneiros inteiros de diferentes grupos genéticos na fase do desmame ao abate aos quatorze meses. Santa Maria: Universidade Federal de Santa Maria, 1997. 136p. Dissertação (Mestrado em Zootecnia) - Universidade Federal de Santa Maria, 1997.

HOGG, B.W. Compensatory growth in ruminants. In: PEARSON, A.M.; DUTSON, T.R. (Eds.) Growth regulation in farm animals. London: Elsevier Science, 1991. p.103-128.

MAKARECHIAN, M.; KUBISCH, H.M.; PRICE, M.A. Effects of date of weaning on subsequent performance of beef cows and their female calves. Canadian Journal of Animal Science, v.68, n.4, p.1035-1040, 1988.

McDONALD, P.; HENDERSON, N.; HERON, S. The biochemistry of silage. 2.ed. Chalcombe Publications, 1991. 339p.

MERTENS, D.R. Análise de fibra e sua utilização na avaliação de alimentos e formulação de rações. In: SIMPÓSIO INTERNACIONAL DE RUMINANTES, REUNIÃO ANUAL DA SOCIEDADE BRASILEIRA DE ZOOTECNIA, 29, 1992, Lavras. Anais... Lavras: Sociedade Brasileira de Zootecnia, 1992. p. 188-219.

MERTENS, D.R. Regulation of forage intake. In: FAHEY Jr., G.C.; COLLINS, M.; MERTENS, D.R. et al. (Eds.) Forage quality, evaluation and utilization. Madison: American Society of Agronomy, Crop Science of America, Soil Science of America, 1994, p.450-493.

MOLETTA, J.L.; PEROTTO, D. Efeito do desmame aos 70 e 210 dias sobre o desempenho ponderal e reprodutivo de vacas de corte. In.: REUNIÃO ANUAL DA SOCIEDADE BRASILEIRA DE ZOOTECNIA, 34., 1997, Juiz de Fora. Anais... Juiz de Fora: Sociedade Brasileira de Zootecnia, 1997. p.397-399.

MOOJEN, J.G.; RESTLE, J.; MOOJEN, E.L. et al. Efeito da época da desmama e da pastagem no desempenho de vacas e terneiros de corte. Desempenho de terneiros. Ciência Rural, v.24, n.2, p.399-403, 1994.

MYERS, S.E.; FAULKNER, D.B.; NASH, T.G. et al. Performance and carcass traits of early-weaned steers receiving either a pasture growing period or a finishing diet at weaning. Journal of Animal Science, v.77, p.311-322, 1999.

NATIONAL RESEARCH COUNCIL - NRC. Nutrient requirements of beef cattle. 7.ed.rev. Washington, D.C.: National Academy of Sciences, 1996. 242p.

OWENS, F.N.; GOETSCH, A.L. Fermentación ruminal. In: CHURCH, D.C. (Ed.) El ruminante, fisiología digestiva y nutrición. Zaragoza: Acríbia, 1993. p.159-190.

PASCOAL, L.L.; VAZ, F.N. Desmame precoce aos sessenta dias. In: RESTLE, J.; BRONDANI, I.L.; PASCOAL, L.L. et al. (Eds.) Técnicas avançadas na recria e engorda de bovinos de corte. Santa Maria: Universidade Federal de Santa Maria, 1997. p.36-50. 
PASCOAL, L.L.; EIFERT, E.C.; RESTLE, J. Nível de proteína bruta para bezerros de corte desmamados aos 66 dias de idade. Revista Brasileira de Zootecnia, v.29, n.5, p.1537-1544, 2000.

PELEGRINI, L.F.V.; PIRES, C.C.; RESTLE, J. Fontes protéicas sobre o desempenho de terneiros confinados. Ciência Rural, v.30, n.3, p.475-479, 2000.

PRESTON, R.L.; WILLIS, M.B. Intensive beef production. 2.ed. Oxford: Pergamnon, 1982. 567p.

RESTLE, J.; FLORES, J.L.C.; VAZ, F.N. et al. Desempenho em confinamento, do desmame ao abate aos quatorze meses, de bovinos inteiros ou castrados, produzidos por vacas de dois anos. Ciência Rural, v.27, n.4, p.651-655, 1997.

RESTLE, J. Confinamento de terneiros. In: RESTLE, J.; BRONDANI, I.L.; PASCOAL, L.L. et al. (Eds.) Técnicas avançadas na recria e engorda de bovinos de corte. Santa Maria: Universidade Federal de Santa Maria, 1997. p.51-67.

RESTLE, J.; VAZ, F.N. Desmame precoce de bezerros. In: SIMPÓSIO INTERNACIONAL SOBRE PRODUÇÃO INTENSIVA DE GADO DE CORTE, 2, 1998, São Paulo. Anais... São Paulo: 1998. p.3-9.

RESTLE, J.; POLLI, V.A.; ALVES FILHO, D.C. et al. Desenvolvimento de bovinos de corte de diferentes grupos genéticos desmamados aos 3 ou 7 meses de idade. Revista Brasileira de Zootecnia, v.28, n.5, p.1023-1030, 1999a.

RESTLE, J.; EIFERT, E.C.; BRONDANI, I.L. et al. Produção de terneiros para abate aos 12 meses, alimentados com silagens de milho colhida a duas alturas de corte, associadas a dois níveis de concentrado. In: REUNIÃO ANUAL DA SOCIEDADE BRASILEIRA DE ZOOTECNIA, 36., 1999, Porto Alegre. Anais... São Paulo: SBZ/Gmosis, [1999b] 17par. CD-ROM. Nutrição de Ruminantes. NUR-143.

RESTLE, J.; BRONDANI, I.L.; FLORES, J.L.C. et al. Desempenho de genótipos de novilhos para abate aos catorze meses, gerados por fêmeas de dois anos. Pesquisa Agropecuária Brasileira, v.34, n.11, p.2123-2128, 1999c.

RESTLE, J.; VAZ, F.N.; PASCOAL, L.L. et al. Efeito do desmame precoce na carcaça de novilhos terminados em pastagem e abatidos aos 24 meses. Pesquisa Agropecuária Brasileira, v.34, n.11, p.2129-2136, 1999d.

RESTLE, J.; ALVES FILHO, D.C.; NEUMANN, M. Eficiência na terminação de bovinos de corte. In: RESTLE, J. (Ed.) Eficiência na produção de bovinos de corte. Santa Maria: Universidade Federal de Santa Maria, 2000. p.277-303.
RESTLE, J.; VAZ. R.Z.; ALVES FILHO, D.C.A. et al. Desempenho de vacas Charolês e Nelore desterneiradas aos três ou sete meses. Revista Brasileira de Zootecnia, v.30, n.2, p.499-507, 2001.

RIBEIRO, E.L.A.; RESTLE, J.; PIRES, C.C. Produção e composição do leite em vacas Charolês e Aberdeen Angus amamentando bezerros puros ou mestiços. Pesquisa Agropecuária Brasileira, v.26, n.8, p.1267-1273, 1991.

RIO GRANDE DO SUL. Governo do Estado do Rio Grande do Sul Lei $n^{\circ} 10.533$, de 03 de agosto de 1995 . Normas técnicas para classificação de carcaças de bovinos e bubalinos para fins de enquadramento no "Programa Carne de Qualidade". Diário Oficial do Estado do Rio Grande do Sul, Porto Alegre, v.54, n.188, p.42-43, 03 de agosto de 1995.

SÁ, I.G.; BARCELLOS, J.O.J.; LOBATO, J.F.P. et al. Efeito do desmame precoce sobre a variação de peso de vacas e bezerros de corte em três sub-épocas de parição. In.: REUNIÃO ANUAL DA SOCIEDADE BRASILEIRA DE ZOOTECNIA, 34., 1997, Juiz de Fora. Anais... Juiz de Fora: Sociedade Brasileira de Zootecnia, 1997. p.400-402.

SAS INSTITUTE. SAS/STAT user's guide: statistics. 4.ed. Version 6, Cary, N.C. v.2, 1993. 943p.

TILLEY, J.M.A.; TERRY, R.A. A two-stage technique for the in vitro digestion of forage crop. Journal British Grassland Society, v.18, n.2, p.104-111, 1963.

Van SOEST, P.J.; WINE, R.H. Use of detergents in analysis of fibrous feeds. IV. Determinations of plant cell-wall constituents. Journal of Association Official Analysis Chemists, v.50, p.50, 1967.

Van SOEST, P.J. Nutritional ecology of the ruminant. 2.ed. Ithaca. 1994. 476p.

VAZ, R.Z. Desenvolvimento e desempenho reprodutivo de novilhas de corte submetidas a diferentes níveis de suplementação durante o período reprodutivo aos 14 meses de idade. Santa Maria: Universidade Federal de Santa Maria, 1998. 98p. Dissertação (Mestrado em Zootecnia) Universidade Federal de Santa Maria, 1998. 